\title{
CONSIDERAÇÕES SOBRE O DIREITO À INTIMIDADE DAS PESSOAS JURÍDICAS
}

\section{Elimar Szaniawski}

Prof. Adjunto do Depto de Direito Civil e Processual Civil da Fac. de Direito do Setor de Ciências Jurídicas da UFPR.

SUMÁRIO: 1. Introảução. 2. Noção de vida privada. 3. Do direito à intimidade das pessoas jurídicas. 4. Da tutela da intimidade das pessoas jurídicas no Brasil. 5. Conclusão.

\section{1) INTRODUÇÃO}

A constituição federal de 05 de outubro de 1988 consagrou, no títuio dedicado aos Direitos e Garantias Fundamentais, no inciso $\mathbf{X}$, đe seu artigo 5 o , a proteção do direito à intimidade e do direito à vida privada, tutelando a nível constitucional duas tipificações dos direitos de personalidade, uma vez que a constituição derrogada não previa a proteção destes atributos da personalidade humana. Não estendeu, porém, o constituinte brasileiro, a proteção constitucional da intimidade, nem da vida privada, às pessoas jurídicas, limitando a tutela constitucional do direito ao recato, genericamente, apenas às pessoas naturais.

A existência de um direito à intimidade ou de um direito ao respeito à vida privada das pessoas jurídicas, é controvertido. A doutrina é praticamente unânime em reconhecer a personalidade aos entes coletivos atribuindo, conseqüentemente, aos mesmos; alguns direitos inerentes aos atributos da personalidade, negando, todavia, a existência de um direito à intimidade ou à vida privada para as pessoas jurídicas.

2) NOÇÃO DE VIDA PRIVADA

A fim de melhor compreendermos a matéria sob exame, convém, analisarmos os conceitos de vida privada e de intimidade: 
Grande parte dos autores brasileiros trata os termos: direito à vida privada, direito à intimidade, direito ao resguardo, direito ao recato, como sinônimos, não traçando qualquer distinção entre vida privada e intimidade. Mas, da análise mais atenta de ambas as figuras jurídicas, infere-se que cada qual apresenta peculiaridades próprias.

O conceito de vida privada ou direito ao respeito à vida privada tem sua origem nas alíneas 2 e 3, do parágrafo $C$, da Reso"ução nọ 428, de 23 de janeiro de 1970, da Assembléia Consultiva do Conselho da Europa, e consiste no conjunto de regras que visam a proteção da vida pessoal e familiar e a intimidade do lar dos indivíduos. Conseqüentemente, trata-se de um direito que cada um tem para assegurar a paz, a tranqüilidade de uma parte de sua vida, a parte que não está consagrada a uma atividade pública. $\mathrm{O}$ direito ao respeito à vida privada diz respeito à vida privada e moral, à honra e à reputação, ao fato de não ser apresentado sob um falso aspecto, à não divulgação de fatos inúteis e embaraçosos, à publicação, sem autorização, de fotografias privadas: à proteção contra a espionagem e às indiscrições injustificáveis ou inadmissíveis, à proteção contra a utilização abusiva de comunicações privadas, à proteção contra a divulgação de informações comunicadas ou recebidas confidencialmente por um particular. Não podem se prevalecer do direito à proteção de sua vida privada as pessoas que por suas próprias atitudes encorajaram indiscrições das quais elas venham a se queixar posteriormente. O respeito à vida privada de uma pessoa ligada à vida pública traz um problema específico. A fórmula "a vida privada cessa onde começa a vida pública" é insuficiente para resolver este problema. As pessoas que representam um papel na vida pública têm direito à proteção de sua vida privada, salvo nos casos em que esta possa ter incidência sobre a vida pública. $O$ fato de que o indivíduo ocupe um lugar na atualidade não o priva do direito ao respeito à sua vida privada. ${ }^{1}$

$\mathrm{O}$ direito à intimidade ou direito à intimidade da vida privada, tem -sido classificado pelos autores, na sua maioria, como uma tipificação do direito de personalidade e subtipificação do direito ao respeito à vida privada, consistindo no direito que toda pessoa possui de se resguardar dos sentidos alheios. Segundo DOTTI, trata-se o direito à intimidade de um conceito mais restrito do que o direito à vida privada, constituindo-se a intimidade em um conceito mais restrito do que vida privada, já que a intimidade consiste em um sentimento que nasce do fundo da alma humana, sendo sua natureza essencialmente espiritual. Já vida privada, 
constitui-se em um conceito mais amplo, estendendo-se a outras . manifestações não tão espirituais. ${ }^{2}$ LINDON parte da análise da Iegislação francesa que tutela o direito ao respeito à vida privada e que utiliza, alternadamente, as expressões: droit au respect de vie privée e droit de l'intimité de la vie privée. ${ }^{3} \mathrm{E}$, para o citado autor, de fundamental importância a distinção de ambos os institutos da vida privada do homem público. É certo que o homem público possui um campo de proteção da vida privada bastante limitado pelo direito do público à informação, direito este, também tutelado pela constituição da maioria dos países. Em razão desta dupla terminologia utilizada pela Lei de 17 de julho de 1970, que trouxe alterações ao artigo $9^{\circ}$ do Código Civil, ocorreu a divisão do direito destinado à tutela da vida privada em: direito ao respeito à vida privada e dive to à intimidade da vida privada, ou, simplesmente, direito à vida privada e direito à intimidade.

Além de prestar-se a distinçäo de direito à vida privada e direito à intimidade para tutelar a limitada esfera secreta da vida do homem público, pelo direito do público à informação, protegendo um círculo mínimo de privacidade que este indivíduo deve possuir para o desdobramento de sua personalidade, que será protegido pelo direito à intimidade, outras situações exigem esta diferenciação. A hipótese da cbrigatoriedade da rejeição de provas judiciais cuja obtenção tenha violado ilicitamente a vida privada de uma das partes.

Os tribunais franceses reservam a utilização de direito à intimidade ou intimidade da vida privada nas causas em que se discute sobre a nudez, as convicções religiosas de alguém e da saúde.

Alguns autores subtipificam o cireito ao respeito à vida privada em direito ao segredo, inserindo-o ao lado do direito à intimidade da vida privada

O direito ao segredo segundo conceito de DE CUPIS', "constitui um aspecto particular do direito ao resguardo. Certas manifestações da pessoa destina-se a conservar-se completamente inacesșíveis ao conhecimento dos outros, quer dizer, secretas; não é apenas ilícito o divulgar tais manifestações, mas tomar delas conhecimento, e o revelá-las, não importa a quantas pessoas". O direito ao segredo tem sido dividido pela doutrina em: direito ao segredo epistolar, direito ao segredo telegráfico, direito ao segredo telefônico, direito ao segredo doméstico e familiar, direito ao segredo profissional e alguns ainda incluem o direito ao segredo documental. O direito ao segredo, segundo COSTA JR. ${ }^{5}$, consiste no: "círculo concêntrico de menor raio em que se desdobra a inti-

R. Fac. Direito Curitiba a. $25 \quad$ n. $25 \quad$ p. $81-92,1989$ 
midäde; é o que reclama proteção mais veemente contra a indiscrição".

O conteúdo do direito à vida privada ou à intimidade ainda não foi perfeitamente caracterizado pela doutrina. Alguns, por exemplo, consideram como pertencentes ao direito à intimidado, integrando esta manifestação da personalidade, o direito sobre a própria imagem, o direito sobre a própria voz, o direito à inviolabilidade de domicílio, o direito ao segredo, o direito ao próprio nome, o direito ao pseudônimo e os direitos morais de autor. Outra corrente já visualiza os citados direitos de personalidade como direitos autônomos. E outros ainda, somente vislumbram a existência de um direito à intimidade e um direito ao segredo, sendo o direito à própria imagem e o direito sobre a própria voz, subtipificações do direito à intimidade.

Pelo fato de não se limitar o direito à intimidade somente à proteção de atentados praticados por terceiros ou pelo Estado nas suas relações com os particulares, mas abranger, também, na própria vida familiar do indivíduo, nas suas relações internas, devendo haver respeito à liberdade familiar entre os cônjuges e nas relações entre pais e filhos no que diz respeito ao segredo da correspondência que salvaguarda a vida privada entre os que se comunicam, surge a noção de um direito à intimidade genérico em oposição às correntes que subtipificam o direito ao recato em diversas subtipificações, englobando neste, o direito ao resguardo e o direito ao segredo. ${ }^{6}$

Desenvolveremos o tema proposta dentro da noção de um conceito de direito à intimidade genérico no dizer de GRINOVER.

\section{3) DO DIREITO À INTIMIDADE}

\section{DAS PESSOAS JURIDICAS}

Conforme vimos, a Constituição do Brasil de 5 de outubro de 1988, tutelou o direito à vida privada e à intimidade entre as garantias individuais sem referir-se à aplicação destes direitos às pessoas jurídicas, seguindo o exemplo das demais constituições dos países livres onde impera o Estado de Direito.

A doutrina apresenta controvérsias e indefinições, negando, alguns a titulariedade da pessoa jurídica ao direito à intimidade ou à vida privada, a exemplo de BRICOLA, FERRARA e TALON ${ }^{7}$, admitindo outros esta titulariedade mas com certos limites, e, outros ainda, não opõe qualquer restrição às pessoas jurídicas serem portadoras de um direito ao respeito à vida privada e um direito à intimidade. ${ }^{8}$ 
O direito alemão, ao adotar a doutrina do direito geral de personalidade reconhece o fato do direito de personalidade estar ligado diretamente ao ser humano, tal como a dignidade, à vida, à integridade corporal e à saúde, entre outras manifestações, não vindo, porém, estes atributos da personalidade humana ao encontro das pessoas jurídicas ou outras entidades não personificadas. O Tribunal Federal (o Bundesgerichtshof) tem, no entanto, garantido a capacidade de função destas pessoas coletivas, surgindo, conseqüentemente, no lugar da proteção do nome da pessoa a tutela da firma, no lugar da tutela da honra, protege-se a boa fama, o crédito e a reputação da pessoa jurídica. $E$, finalmente, no lugar da proteção das esferas íntima e privada do indivíduo surge atutela da empresa e dos segredos comerciais e industriais ou outras conveniências da entidade. Mas cumpre ressaltar que o próprio Tribunal Federal alemão, expressamente, admite que a proteção das atividades comerciais e industriais das pessoas jurídicas possui um âmbito muito mais restrito do que a tutela das pessoas naturais. ${ }^{9}$

KAYSER posiciona-se entre os defensores da extensão da proteção da privacidade às pessoas jurídicas, entendendo ser possível reconhecer às mesmas um direito análogo ao direito ao respeito à vida privada, que se destinaria a proteger a vida interna da entidade contra as investigações e as divulgações que lhe sejam inconvenientes e prejudiciais. Advoga o autor a possibilidade de os segredos dos negócios de empresas serem tutelados como proteção da vida privada e não somente em relação ao direito aos segredos industriais ou de fábrica e das invenções, mas de um modo geral, toda a organização empresarial, tal como a composição e organização dos seus quadros de pessoal, os contratos e convenções realizados com outras entidades coletivas, a clientela, os correspondentes, os projetos de extensão e ampliação, os créditos e estoques, entre outros. Atribai ainda o autor às pessoas jurídicas o direito de resposta como defesa de sua personalidade e o direito de retificação em relação as divulgações errôneas ou equivocadas sobre as pessoas jurídicas. ${ }^{10}$

Não devemos olvidar que em França, por ocasião daś discussões do projeto de lei que se transformou, posteriormente, na Lei no 70-643, de 17 de julho de 1970, foi levantada a tese de que os segredos dos negócios de uma empresa estariam tutelados por aquelas normas, tal como os segredos das pessoas naturais. Duas correntes se constituíram, sendo que uma defendia a possibilidade de os segredos das empresas serem protegidos pelo artigo 90, alínea 1, do Código Civil. A outra, excluia esta possibilidade.

\begin{tabular}{llllll}
\hline R. Fac. Direito Curitiba & a. 25 & n. 25 & p. 81-92, 1989 & 85
\end{tabular}


Esta polêmica teve grande repercussão nos meios jurídicos, tendo dirimido a controvérsia, o Ministro da Justiça, em resposta as ponderações de um deputado, defensor da primeira tese, afirmando pela impossibilidade de se incluir e tutelar os segredos de uma empresa como proteção ao direito ao respeito à vida privada pelo fato de os segredos de empresas não se poderem conter dentro de uma noção de direito ao respeito à vida privada, ou direito à intimidade da vida privada como um direito de personalidade. ${ }^{11}$

No Brasil pouco se escreveu sobre o assunto, negando RENE ARIEL DOTTI a possibilidade dos entes coletivos possuirem um direito à intimidade por: "constituir um núcleo de privacidade, ser um 'sentimento', um 'estado de alma' que se projeta ao extremo com o fim de gozar a liberdade de amar, pensar, chorar, rir, enfim, de viver a própria vida e de morrer a própria morte'.'12 Por isto, apesar de reconhecer às pessoas jurídicas o exercício de certos direitos inerentes à personalidade, apenas atribui o direito à intimidade à pessoa natural.

COSTA JR. por sua vez, não descarta, teoricamente, a extensão do direito à intimidade às pessoas jurídicas. Vislumbra, porém, uma imensa dificuldade em individuar uma vida privada da pessoa jurídica que não seja a soma das diversas vidas privadas de seus vários componentes. ${ }^{13}$

ADA GRINOVER apesar de não ter enfrentado diretamente o tema em sua brilhante tese para o cargo de Professor Titular de Processo Penal na Universidade de São Paulo14, atribui às pessoas jurídicas a titulariedade do direito à liberdade e ao sigilo da correspondência e das comunicações.

\section{4) DA TUTELA DA INTIMIDADE DAS PESSOAS JURIDICAS NO BRASIL}

O direito à intimidade de uma pessoa jurídica não pode ser analisado do mesmo modo que o direito à intimidade da pessoa natural devido suas peculiaridades. Convém recordarmos que as regras jurídicas que regulam o nascimento e a personificação dos entes coletivos são diversas daquelas que dispõe sobre as pessoas naturais. Os fins de ambas as categorias de pessoas também são outros, daí a diversidade de tratamento que ambas as espécies de pessoas possuem. Cada qual com normas próprias. O fato da pessoa jurídica ter personalidade reconhecida pela ordem jurídica faz com aue automaticamente devam ser reconhecidos e tutelados os atributos e prolongamentos desta personalidade.

A corrente tipificadora e îracionária dos direitos de persona-

Curitiba

a. 25

n. 25

p. 81-92, 1989 
lidade tem reconhecido que a pessoa jurídica deve possuir também alguns direitos inerentes à sua personalidade, a saber: o direito ao nome ou à firma, o direito ao sinal figurativo, o direito à liberdade, o direito ao sigilo de suas comunicações, o direito à boa fama e um direito de resposta. ${ }^{15}$

Efetivamente, não podemos endossar o pensamento de alguns autores para os quais o principal motivo para negar o direito às pessoas jurídicas de serem titulares de um direito à intimidade, reside no fato de que todos os atos das pessoas coletivas estejam sujeitos à publicidade. Afirmam estes autores a idéia de os entes coietivos possuirem uma esfera de privacidade não passar de um contra-senso lógico devido as finalidades destas entidades. Evidentemente possuem as pessoas jurídicas como caracteríística a publicidade de seus atos, a exemplo de seu ato constitutivo, da alteração do contrato social, e do seu capital social, que são obrigatoriamente levados ao registro público. Mas isto não significa que as pessoas coletivas não devam ter assegurada uma esfera de privacidade na qual terceiros, estranhos à entidade, estejam impedidos de se imiscuir, de realizar investigações e de espionar a atividade da pessoa jurídica por qualquer forma que seja. Apesar de reduzida, toda pessoa jurídica necessita de uma esfera de privacidade e um direito ao segredo para poder se desenvolver livremente $\mathrm{e}$ atingir às finalidades colimadas em seu ato constitutivo.

Admitindo-se teoria que defende a existência de um direito âo respeito à vida privada em sentido amplo, constituído pelo direito à vida privada, pelo direito à própria imagem e pelo direito ao segredo, ou como preferem alguns, a denominação de direito à intimidade genérico, ${ }^{16}$ não haverá maior problema em atribuir às pessoas jurídicas a titulariedade de um direito à intimidade genérico.

A legislação brasileira já há longa data tem tutelado aspectos da. vida privada das pessoas jurídicas, assegurando, expressamente, a proteção do direito ao segredo no artigo 17 do Código Comercial, o direito ao segredo da escrita comercial, limitando-se apenas este direito ao sigilo, na necessidade de exibição judicial dos livros comerciais, nos casos legais, ${ }^{17}$ sendo, porém, obrigatória tal exibição nas vistas do empresário a quem pertençam tais livros, ou de seu representante legal. Os livros comerciais das sociedades anônimas também encontram exceção ao direito ao sigilo em grau absoluto nas hipóteses de exibição judicial, nos termos do artigo 105, da Lei no 6.404 de 1976. E assegurado o direito ao sigilo das comunicações das pessoas, no inciso XII, do artigo 50 tuição Federal, não havendo qualquer impedimento da extensão

$\begin{array}{llllll}\text { R: Fac. Direito Curitiba } & \text { a. } 25 & \text { n. } 25 & \text { p. } 81-92,1989 & 87\end{array}$


deste direito do sigilo das comunicações às pessoas jurídicas. Igualmente, encontram-se tutelados em nosso direito positivo, o direito ao segredo de fábrica e ao segredo de negócio, nos incisos XI e XII, do Decreto-lei no 7.903 de 27 de agosto de 1945, mantidos em vigor pelo artigo 128, da Lei no 5.772 de 21 de dezembro de 1971, e não revogados pela Lei no 7.209 , de 11 de julho de 1984, que deu nova redação à parte geral do Código Penal em vigor, apesar da idéia de alguns, que entendem não pertencerem tais direitos à categoria de direitos de personalidade, a exemplo de FERRARA. Também é garantido o direito ao segredo da situação econômica e financeira das pessoas coletivas para qualquer finalidade, por parte da Fazenda Pública e de seus funcionários, constituindo-se os segredos obtidos por estes, em direito ao sigilo profissional, sobre negócios e atividades daquelas, consoante previsão do artigo 198, da Lei no 5.172 de 25 de outubro de 1966. Encontramos apenas limites a esta norma, devendo a Fazenda Pública prestar informações sobre negócios e atividades de pessoas jurídicas ou naturais, quando houver requisição de informações por um magistrado, com fundamento no interesse da boa administração da justiça, de acordo com o parágrafo único do mencionado artigo. Também está a pessoa jurídica assegurada no tocante ao sigilo de sua situação financeira e patrimonial perante a Fazenda Pública, já que a lei expressamente veda os agentes e serventuários públicos de divulgarem, para qualquer finalidade, as informações que possuem decorrentes de seu ofício, sobre a situação econômica, financeira e patrimonial da pessoa coletiva, constituindo-se este em um direito ao sigilo profissional aue possui a pessoa jurídica, contribuinte. Limita-se este direito ao sigilo da pessoa jurídica contra agentes e funcionários públicos detentores de seus segredos por decorrência de seu ofício ou profissão, na obrigação destes serventuários da justiça prestarem informações sobre a situação econômica e patrimonial do contribuinte nos casos de assistência para a fiscalização e permuta de informações que fazem entre si as Fazenda Pública da União, dos Estados, dos Municípios e do Distrito Federal, de acordo com o estabe'ecido por lei ou convênio, nos termos do artigo 199 do Código Tributário Nacional, e mediante requisição da autoridade judiciária no interesse da boa administração da justiça.

A exemplo das pessuas naturais, têm igualmente as pessoas jurídicas a proteção das suas atividades e negócios através do direito ao sigilo bancário no que diz respeito às suas operações ativas, passivas e serviços prestados por bancos e agentes financeiros a estas, constituindo-se em delito a quebra do sigilo bancá-

a. 25

n. 25

p. 81-92, 1989 
rio, nos termos da Lei no 4.595 de 31 de dezembro de 1964. Encontram-se apenas exceções a este direito ao sigilo em grau absoluto na hipótese de pedido de requisição de informações sobre a atividade econômica e financeira da pessoa jurídica pelo magistrado, quando houver manifesto interesse na boa administração da justiça.

Pelo exposto concluimos que existe no direito brasileiro a proteção à vida privada e à intimidade das pessoas jurídicas no tocante aos seus negócios, atividade econômica e situação financeira, caracterizando-se este dever de sigilo como dever de segredo profissional, tanto devidos pela Fazenda Pública, como por seus serventuários, encontrando-se os limites ao dever de segredo em grau absoluto diante de requisição judiciária quando as informações requisitadas interessarem à boa administração da justiça, aplicando-se o mesmo critério em relação ao direito ao sigilo bancário, isto é, no dever de todos os litigantes prestarem informações ao juiz, quando este o determinar.

Conseqüentemente, é inegável a tutela que possui a pessoa jurídica no tocante ao seu direito à intimidade genérico, pelo direito brasileiro.

\section{5) CONCLUSÃO}

Constata-se pelo exposto que os autores que adotam as subtipificações do direito ao respeito à vida privada ou direito à intimidade genérico, considerando-os direitos autônomos, têm poucos argumentos para justificar a exclusão de sua aplicação também às pessoas jurídicas. A pessoa jurídica, insistimos, só pode se desenvolver e cumprir suas finalidades estatutárias e contratuais se existir para as mesmas uma esfera secreta, que impossibilite a aproximação indesejada dos olhos e ouvidos alheios ou qualquer outra forma de indiscrição, o que é imprescindível para sua existência. Não só necessita a pessoa coletiva de sigilo em relação à sua escrita comercial, às suas operações bancárias, mas toda a atividade empresarial necessita de um certo grau de segredo. A estratégia de marketing, o lançamento de um novo produto ou de um novo modelo de um produto ao mercado, toda esta atividade, não falando nem de marca, nem de segredo industrial, mas, simplesmente, toda a operação de lançamento ao mercado necesșita de sigilo, podendo apenas conhecer todos os planos dirigentes do mais elevado escalão da administração da pessoa jurídica, isto é, - cérebro da entidade. Quem de foro espionar, interceptar comunicação, gravar ou fotografar de longe as atividades da pessoa

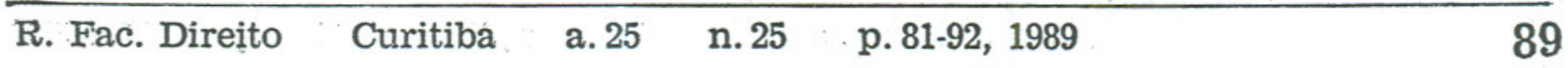


jurídica, a exemplo das preparações, ensaios de modelos, etc., não estará atentando contra a intımidade geral do presidente ou de alguns dos diretores da entidade, nem contra a intimidade genérica de seus sócios, mas sim, contra o direito geral à intimidade da própria entidade coletiva. Os prejuízos decorrentes dos atos de indiscrição praticados por terceiros, através da intrusão na intimidade da pessoa coletiva não serão de seu presidente, nem dos sócios, e muito menos dos funcionários da pessoa jurídica, que tem seus salários e direitos garantidos por lei. Quem sofrerá os danos pelos ilícitos praticados será somente a pessoa jurídica, não a pessoa de seus sócios e muito a soma das vidas privadas de seus vários componentes, pessoas naturais.

Em relação às pessoas jurídicas de direito público entendemos que podem estas ser vítimas de atentados em seu direito à intimidade genérico, apesar de ser muito mais difícil a individuação de vida privada nestas pessoas do que nas pessoas jurídicas de direito privado. Mas toda pessoa jurídica de direito público e, especialmente, as entidades descentralizadas da administração pública indireta necessitam, e possuem uma esfera secreta onde as mesmas possam se desenvolver e cumprir com suas funções específicas. ${ }^{18}$

Dentro destas idéias, somos partidários pelo reconhecimento do direito geral à intimidade, às pessoas jurídicas, de um modo geral. Lembramos aue na própria França, ainda permanecem acirradas as discussõ̃es em relação a extensão e aplicação da Lei de 17 de julho de 1970, na tutela do direito à intimidade genérico das pessoas coletivas, engrossando, a cada dia, a corrente daqueles que admitem possuirem, as pessoas jurídicas, um direito ao respeito à vida privada tutelado pela citada lei especial.

Obviamente entendemos que o direito à intimidade genérico das pessoas jurídicas é diverso e não se identifica perfeitamente com o direito geral à intimidade das pessoas naturais. Não possui a pessoa jurídica uma vida familiar. Mas durante sua existência, cresce, se desenvolve e cumpre suas funções sociais e pessoais, necessitando, portanto, de uma esfera íntima que possibilite este desenvolvimento e o cumprimento de sua função social.

É dever do poder público assegurar o livre desdobramento tanto da personalidade da pessoa natural como da pessoa jurídica protegendo sua dignidade. $\mathbf{E}$ de conteúdo constitucional, sob o ponto de vista do quadro hierárquico de normas, devendo, por esta razão, ser tutelada constitucionalmente a intimidade de modo genérico, das pessoas jurídicas, impedindo deste modo a intrusão e as formas de indiscreção no seio das entidades coletivas,

Curitiba

a. 25

n. 25

p. 81-92, 1989 
cessando a infrutífera polêmica da doutrina, que discute sobre a possibilidade ou não da tutela da intimidade da pessoa jurídica podendo, assim, o legislador brasileiro, elaborar leis que venham a tutelar tanto a intimidade de um modo geral das pessoas naturais como das pessoas jurídicas.

\section{NOT A S}

(1) Cf. texto das alíneas 2 e 3 , do parágrafo $C$, da Resolução n. $428 / 70$, da Assembléia Consultiva do Conselno da Europa.

(2) DOTTI, in Proteção da vida privada e liberdade de informação, pág. 69.

(3) LINDON, in Les droits de la personnalité, dictionnaire juridique, págs. 296 e segs.

(4) DE CUPIS, Os direitos da personalidade, pág. 147.

(5) COSTA JR., O direito de estar só, pág. 73.

(6) A. P. GRINOVER, Liberdades públicas e processo penal, pág. 86.

(7) F. BRICOLA, in Prospettive e limiti della tutela penale della riservatezza, Riv. Ital. de Dir. e Proc. Pennale, 1967, pág. 63; F. FERRARA, Trattato di dirito civile italiano, vol., I, parte, I, pág. 394; D. TALON, Encyclopédie Daloz de Droit Civil, t. 4, n. ${ }^{\circ} 42$.

(8) DE CUPIS, Os direitos da personalidade, pág. 26.

(9) Coletânea de Jurisprudência do B.G.H.Z., vol. 36,77 e BGH. VersR. 1975,332 pág. 72.

(10) KAYSER, in La protection de la vie privée, pág. 162.

(11) J. O., 29 de maio de 1970, pág. 2.074.

(12) DOTTI, ob. cit., pág. 94.

(13) COSTA JR., in O Direito de Estar Só, págs. 56 e 57.

(14) ADA PELEGRINI GRINOVER, in Liberdades Públicas e Processo Penal, pág, 189.

(15) FERRARA, in Trattado di diritto civile italiano, vol. I, parte I, pág. 393, exclui dos direitos de personalidade os direitos sobre bens imateriais, a exemplo dos direitos autorais, direitos de invenção e marcas de fábrica, pois estes recaem sobre bens externos e de caráter patrimonial.

(16) - Adotam esta terminologia, GRINOVER, ob. cit., pág. 86 e GIANOTTI, in A Tutela Constitucional da Intimidade, pág. 65 e seg.

(17) O artigo 195 da Lei n. 5.172/66, revogou em parte; o artigo 17, do: Código Comercial para efeitos de fiscalização tributária, bem como o artigo: 145, e seu parágrafo único, do Decreto n. 77.077 , de 24 de janeiro de 1976, que faculta aos órgãos da Previdência Social, a verificação dos livros e fichas comerciais, revogando, os artigos 17 e 18, do citado código. A própria legislação pertinente à inspeção do trabalho, Decreto n. 55.841 de 15 de março de 1965, determina aos empregadores a exibição obrigatória aos fiscais ou Agentes da Inspeção do Trabalho a exibição de livros, fichas de todos os documentos relativos aos seus empregados e relações de emprego e previdência social. As pessกas jurídicas também são obrigadas a receber agentes para a fiscalização para efeitos de saúde pública.

\begin{tabular}{lllll}
\hline R. Fac. Direito Curitiba & a. 25 & n. 25 & p. $81-92,1989$ & 91
\end{tabular}


(18) Não só as pessoas jurídicas de direito público descentralizadas podem possuir um direito à intimidade de modo genérico ofenđido por terceiros, mas também a pessoa jurídica de direito público interno, da administração direta, como pode ser constatado no seguinte exemplo: na hipótese em que determinado caso seja julgado pelo Poder Judiciário, devendo a causa tramitar e ser decidida em segredo de justiça. Para isto determina o magistrado a proibição expressa de ser o julgamento fotografado, filmado ou gravado. Se, no entanto, determinado técnico instalar previamente aparelhos eletrônicos que registrem imagens e sons do mencionado julgamento, vindo o mesmo a ser divulgado publicamente, pergunta-se: quem é a vítima de atentado ao direito ao segredo ou à intimidade genérico? $\mathrm{O}$ autor? $\mathrm{O}$ réu? Ou o próprio Estado através do seu órgão jurisdicional ofendido pela desobediência praticada mediante indiscrição? $\mathbf{E}$ inegável que os litigantes são atingidos pelo atentado ao seu direito ao segredo pela realização clandestina dos registros do julgamento e também pela indevida divulgação destes fatos registrados ao público. Mas a grande vítima destes atentados é o Estado-juiz que teve suas determinações descumpridas através de intrusão e investigação indevida de suas atividades funcionais e pela. indevida divulgação de pormenores ocorridos no recintodo tribunal.

\section{BIBLIOGRAFIA}

(1) BRICOLA, Franco, Prospettive e limiti della tutela penale del la riservatezza, Riv. it. de Dir. e Proc. Penale, 1967, p. 03.

(2) COSTTA JR., José Paulo da, O direito de estar só, R.T., São Paulo, 1967.

(3) DE CUPIS, Adriano, Os direitos da personalidade, Livraria e Editora Morais, Iisboa, 1961.

(4) DOTTI, Renê Ariel, Proteção da vida privada e liberdade de informação, R.T., São Paulo, 1980.

(5) FERRARA, Francesco, Trattado di diritto civile italiano, vol. II, parte I, Athenaeum, 1921.

(6) GRINOVER, Ada Pellegrini, Liberdades públicas e processo penal, R.T., 2.* ed., São Paulo, 1982.

(7) KAYSER, Pierre, La protection de la vie privée, ed. Economica, Paris, 1984.

( 8) LINDON, Raymond, Les droits de la personnalité - dictionnaire juridique, Dalloz, 1983.

(9) SZANIAWSKI, Elimar, Os direitos de personalidade e sua tutela, tese, U.F.Pr., 1989.

(10) TALON, D., Encyclopédie Dalloz de droit civil, tome 4, verbete n. 42.

(11) COLETANEA DE JURISPRUDENCIA DO BUNDESGERICHTSHOF, vol. 36.

(12) JOURNAL OFFICIEL de 20 de maio de 1970.

(13) RESOLUÇÃO n. 428/70 da Assembléia Consultiva do Conselho da Europa, 1970. 